Article

\title{
Effect of the Addition of Amine in Organophosphorus Compounds on Molecular Structuration of Ionic Liquids-Application to Solvent Extraction
}

\author{
Soumaya Gmar ${ }^{1}$, Fabrice Mutelet ${ }^{2}$ and Alexandre Chagnes ${ }^{1, *(1)}$ \\ 1 Université de Lorraine, CNRS, GeoRessources, F-54000 Nancy, France; soumaya.gmar@univ-lorraine.fr \\ 2 Laboratoire Réactions et Génie des Procédés, Université de Lorraine, 1 rue Grandville, \\ BP 20451 Nancy, France; fabrice.mutelet@univ-lorraine.fr \\ * Correspondence: alexandre.chagnes@univ-lorraine.fr
}

Academic Editors: Magdalena Regel-Rosocka and Isabelle Billard

Received: 11 April 2020; Accepted: 1 June 2020; Published: 2 June 2020

\begin{abstract}
Variation of dynamic viscosity, density and enthalpy as a function of mole fraction of amine (tri-n-octylamine, triisooctylamine, bis(2-ethylhexyl)amine) in bis(2-ethylhexyl) phosphoric acid (D2EHPA) or Cyanex 272, (bis(2,4,4-trimethylpentyl)phosphinic acid) has been determined at $25^{\circ} \mathrm{C}$. Valuable information regarding structuration and destabilization of the corresponding ionic liquids has been deduced from these data. A simple model describing the variation of dynamic viscosity as a function of mole fraction of amine has been used to determine the speciation in these mixtures. Extraction tests of cobalt(II) and nickel(II) by D2EHPA-amine mixtures have shown the highest cobalt(II)-nickel(II) selectivity has been achieved with D2EHPA-2-ethylhexylamine mixture as cobalt(II) extraction efficiency of $77 \%$ was obtained, while no significant nickel(II) extraction was observed at a chloride concentration of $3 \mathrm{~mol} \cdot \mathrm{L}^{-1}$.
\end{abstract}

Keywords: viscosity; molar volume; heat of mixture; solvent extraction; ionic liquids

\section{Introduction}

Liquid-liquid extraction is a mature technology usually used in hydrometallurgy to recover metals from leaching solution mainly produced by acid digestion of primary and secondary resources [1]. This method relies on the contact of the aqueous leaching solution with a non-miscible organic solvent composed of an extractant, a diluent, and in some cases a phase modifier. Solvent extraction efficiency and selectivity mainly depends on the formulation of the extraction solvent. In particular, the chemical structure of extractant plays a crucial role [1,2]. Therefore, more and more studies are focused on synthesis of new extractants in order to improve the efficiency and the selectivity of solvent extraction processes [3,4]. Another approach consists in mixing commercial extractants to formulate new solvents exhibiting synergistic properties, i.e., a significant increase in extraction efficiencies towards targeted metals. In such synergistic systems, the distribution ratio obtained by mixing two extractants is greater than the sum of either extractant functioning alone. In other words, the synergistic effect can be assayed by calculating the synergistic coefficient $S C$ expressed as follows $[5,6]$ :

$$
S C=\frac{D_{\operatorname{mix}}}{D_{A}+D_{B}}
$$

where $D_{A}$ and $D_{B}$ are the distribution ratios of the metal ion by single extractant $\mathrm{A}$ and $\mathrm{B}$, while $D_{m i x}$ represents the distribution ratio by the mixture of $\mathrm{A}$ and $\mathrm{B}$. 
Usually, synergistic effects take place when solvating and acidic compounds are mixed together because solvating molecules improves the extraction by rendering the complex more liphophilic (replacement of water molecules in the first coordination sphere of metal ion) [1]:

$$
M^{n+}+n \overline{H L}+x \bar{S} \rightleftharpoons \overline{M L_{n} S_{x}}+n H^{+}
$$

In Equation (2), $M^{n+}$ is metal ion, $H L$ is acidic extractant, $S$ is organophosphorus compound and the overline bars denote the species in the organic phase.

The enhancement of the distribution ratio can be as high as $10^{6}$ and is attributed to the higher solubility of the synergistic adduct in the organic phase.

Synergistic effects were also reported by mixing amine and organophosphorus acid [7-13]. For instance, Liu et al. [10] showed synergistic extraction of rare-earth elements (REE) by mixing organophosphorus compounds such as Cyanex 272 (bis(2,4,4-trimethylpentyl)phosphinic acid), PC88A (2-ethylhexyl-2-ethylhexyl phosphonic acid) or D2EHPA (bis(2-ethylhexyl)phosphoric acid) with Alamine 336 (a blend of octyl and decyl tertiary amines). In such systems, it was observed that the synergistic coefficient (SC, Equation (1)) for the extraction of REEs by binary mixtures of $0.5 \mathrm{~mol} \cdot \mathrm{L}^{-1}$ organophosphorus acid and $0.5 \mathrm{~mol} \cdot \mathrm{L}^{-1}$ Alamine 336 depends on the nature of the extractants and the targeted metal. Indeed, SC decreased in the following order: Cyanex $272(\mathrm{SC}(\mathrm{La})=5.5, \mathrm{SC}(\mathrm{Ce})=25.7$, $\mathrm{SC}(\mathrm{Pr})=105.7$, and $\mathrm{SC}(\mathrm{Nd})=66.2)>\mathrm{PC} 88 \mathrm{~A}(\mathrm{SC}(\mathrm{La})=2.0, \mathrm{SC}(\mathrm{Ce})=6.2, \mathrm{SC}(\mathrm{Pr})=6.3$, and SC $(\mathrm{Nd})=$ $6.8)>$ D2EHPA $(\mathrm{SC}(\mathrm{La})=0.86, \mathrm{SC}(\mathrm{Ce})=0.90, \mathrm{SC}(\mathrm{Pr})=1.06$ and $\mathrm{SC}(\mathrm{Nd})=1.08)$.

Liquid-liquid extraction of metal cations by organophosphorus compounds occurs typically according to a cationic exchange equilibrium:

$$
M^{n+}+n \overline{H L} \rightleftharpoons \overline{M L_{n}}+n H^{+}
$$

When introducing an amine into the organic phase containing an organophosphorus acid, strong interactions between the organophosphorus acid and the organic amine occur resulting in the formation of a stable ion pair adduct [14]:

$$
M^{n+}+n \overline{H L}+x \overline{R_{3} N} \rightleftharpoons \overline{M L_{n} \cdot m R_{3} N}+n H^{+}
$$

Such a reaction may change the extraction efficiency in either a positive (synergism, SC $>0$ ) or a negative (antagonism, SC $<0$ ) way depending on the interactions and speciation in solution, which depends at their turn on the chemical structure of amines and organophosphorus acids.

Therefore, it is of great interest to investigate speciation and interactions in mixtures of amines and organophosphorus acids as a function of the nature of these reagents and their mole fraction. For this goal, dynamic viscosity, density and heat measurements have been carried out in mixtures of several amines (tri-2-ethylhexylamine, triisooctylamine, tri-n-octylamine triisooctylamine, tri-n-octylamine) and organosphosphorus acids (D2EHPA or Cyanex 272). For the first time, viscosity measurements have been used to determine the stoichiometry of the species as a function of the composition of amine-organophosphorus acid mixtures. The resulting extraction efficiencies of cobalt(II) by amine-D2EHPA mixtures and the selectivity towards nickel(II) have been finally determined and discussed in the light of the speciation in organic phase and chemical structures of amines.

\section{Material and Methods}

Tri-2-ethylhexylamine (TEHA, Aldrich, France, purity > 97\%), triisooctylamine (TIOA, Aldrich, technical grade), tri-n-octylamine (TOA, Aldrich, France, purity $=98 \%$ ), tri-n-octylamine (Aldrich, France, purity $=98 \%$ ), bis (2-ethylhexyl)phosphoric acid (D2EHPA) (Aldrich, France, purity $=98 \%$ ), Cyanex 272 (Solvay, Niagara Falls, Ontario, Canada) were used without any further purification. Mixtures were prepared by weighting the appropriate amount of amine and organophosphorus acid by using a Mettler Toledo MS-TS balance (4 digits). 
$\mathrm{CoSO}_{4} \cdot 7 \mathrm{H}_{2} \mathrm{O}, \mathrm{NiCl}_{2}, \mathrm{NaCl}$ and $\mathrm{HCl}$ (Aldrich, purity $=98 \%$ ) were used to prepare feed solutions for liquid-liquid extraction experiments. Feed solutions of $\mathrm{Ni}(\mathrm{II})$ and $\mathrm{Co}(\mathrm{II})$ at $0.008 \mathrm{~mol} \cdot \mathrm{L}^{-1}$ were prepared by dissolving the required amount of salts in $0.1 \mathrm{~mol} \cdot \mathrm{L}^{-1}$ hydrochloric acid solutions containing various amount of sodium chloride in order to obtain aqueous solution containing total chloride concentrations varying from $1 \mathrm{~mol} \cdot \mathrm{L}^{-1}$ and $5 \mathrm{~mol} \cdot \mathrm{L}^{-1}$.

Density and viscosity were determined using an Anton Paar DMA 4500M combined densimeter viscometer (Anton Paar, Paris, France). The sample was introduced into a U-shaped borosilicate glass tube that was being excited to vibrate at its characteristic frequency. The characteristic frequency changed depending on the density and the viscosity of the sample. The combined densimeter viscometer was calibrated with air, demineralized water, tri-n-octylamine and D2EHPA at $20{ }^{\circ} \mathrm{C}$. The viscosity and density values of tri-n-octylamine, Cyanex 272 and D2EHPA were compared with those previously reported in the literature [15] and good agreements were found.

Calorimetric measurements were carried out in a Setaram C80 calorimeter (Setaram, Paris, France) at $25{ }^{\circ} \mathrm{C}$ and atmospheric pressure. A full description of the procedure is given in the previous work [16]. In a few words, a cylindrical reversal-mixing cell containing two compartments was used. The amine and D2EHPA or Cyanex 272 were placed in the bottom and top compartments, respectively. Temperature of the calorimeter was maintained during $3 \mathrm{~h}$ before measurements. The calorimeter was then turned $180^{\circ}$ until the maximum heat flux is reached. The movable cap used to separate the compounds allowed to obtain good mixing. The apparatus uncertainty was evaluated at $\pm 3 \%$.

Liquid-liquid extraction experiments were carried out by mixing $10 \mathrm{~mL}$ of aqueous phases and $10 \mathrm{~mL}$ of the aqueous of organic phases for $15 \mathrm{~min}$ at $150 \mathrm{rpm}$ at room temperature by means of a Gerhard thermoshaker (Grhard, Strasbourg, France). Organic and aqueous phases were separated after centrifugation at $3000 \mathrm{rpm}$ for $2 \mathrm{~min}$ with a SIGMA 2-16P centrifuge (VWR, Paris, France). Nickel and cobalt concentrations in the aqueous phases after liquid-liquid extraction were determined by measuring the absorbances of the aqueous phase at $410 \mathrm{~nm}$ and $511 \mathrm{~nm}$, respectively, by means of a Cary $60 \mathrm{UV}-\mathrm{Vis}$ spectrometer (UV-Vis cube with a pathway length of $1 \mathrm{~cm}$ ) (Agilent, Paris, France). Metal ion concentration transferred from the aqueous phase into the organic phase was then deduced by mass balance in order to calculate the extraction efficiencies and the distribution ratios of nickel and cobalt. Experiments were duplicated and the experimental error on the distribution coefficients of metals was estimated to be within $5 \%$.

Tables 1-3 gathers the experimental values of viscosity, density and enthalpy for the mixtures of amine and D2EHPA or Cyanex 272 as a function of mole fraction of an amine.

Table 1. Viscosities and densities for D2EHPA-amine mixtures at $25{ }^{\circ} \mathrm{C}$ (uncertainties on mole fraction $= \pm 0.1 \%$, dynamic viscosity $= \pm 2 \%$, density $= \pm 0.2 \%$ ).

\begin{tabular}{|c|c|c|c|c|c|c|}
\hline \multirow[b]{2}{*}{$x$ (amine) } & \multicolumn{2}{|c|}{ D2EHPA-TEHA } & \multicolumn{2}{|c|}{ D2EHPA-TIOA } & \multicolumn{2}{|c|}{ D2EHPA-TOA } \\
\hline & $\eta(\mathrm{cP})$ & $\rho\left(g \cdot L^{-1}\right)$ & $\eta(c P)$ & $\rho\left(g \cdot L^{-1}\right)$ & $\eta(\mathrm{cP})$ & $\rho\left(g \cdot L^{-1}\right)$ \\
\hline 0.00 & 36.3 & 0.972 & 36.3 & 0.972 & 36.1 & 0.972 \\
\hline 0.13 & 324.7 & 0.960 & 172.9 & 0.956 & 147.3 & 0.955 \\
\hline 0.14 & 395.1 & 0.958 & 202.2 & 0.955 & 176.9 & 0.953 \\
\hline 0.17 & 502.9 & 0.956 & 226.7 & 0.954 & 220.7 & 0.950 \\
\hline 0.19 & 633.9 & 0.953 & 304.8 & 0.950 & 325.2 & 0.945 \\
\hline 0.25 & 934.0 & 0.944 & 686.7 & 0.940 & 470.4 & 0.938 \\
\hline 0.33 & 788.4 & 0.930 & 1305.1 & 0.930 & 744.5 & 0.927 \\
\hline 0.39 & 561.5 & 0.918 & 1679.8 & 0.923 & 824.1 & 0.917 \\
\hline 0.48 & 335.7 & 0.900 & 1027.9 & 0.901 & 420.3 & 0.898 \\
\hline 0.58 & 204.2 & 0.882 & 402.9 & 0.886 & 163.5 & 0.878 \\
\hline 0.79 & 61.7 & 0.847 & 71.2 & 0.848 & 31.4 & 0.837 \\
\hline 1.00 & 17.5 & 0.815 & 11.0 & 0.813 & 8.3 & 0.808 \\
\hline
\end{tabular}


Table 2. Viscosities and densities for Cyanex 272-amine mixtures at $25{ }^{\circ} \mathrm{C}$ (uncertainties on mole fraction $= \pm 0.1 \%$, dynamic viscosity $= \pm 2 \%$, density $= \pm 0.2 \%$ ).

\begin{tabular}{|c|c|c|c|c|c|c|}
\hline \multirow[b]{2}{*}{ x (amine) } & \multicolumn{2}{|c|}{ Cyanex-TEHA } & \multicolumn{2}{|c|}{ Cyanex-TIOA } & \multicolumn{2}{|c|}{ Cyanex-TOA } \\
\hline & $\eta(\mathrm{cP})$ & $\rho\left(g \cdot L^{-1}\right)$ & $\eta(\mathrm{cP})$ & $\rho\left(g \cdot L^{-1}\right)$ & $\eta(\mathrm{cP})$ & $\rho\left(g \cdot L^{-1}\right)$ \\
\hline 0.00 & 124.2 & 0.815 & 124.9 & 0.813 & 124.6 & 0.808 \\
\hline 0.13 & 83.8 & 0.832 & 400.0 & 0.834 & 325.0 & 0.829 \\
\hline 0.15 & 80.3 & 0.850 & 480.0 & 0.853 & 353.2 & 0.850 \\
\hline 0.18 & 75.6 & 0.859 & 537.0 & 0.866 & 390.4 & 0.862 \\
\hline 0.20 & 70.3 & 0.867 & 562.5 & 0.874 & 404.7 & 0.875 \\
\hline 0.24 & 65.8 & 0.875 & 489.9 & 0.883 & 340.1 & 0.881 \\
\hline 0.27 & 56.5 & 0.885 & 435.8 & 0.895 & 299.7 & 0.893 \\
\hline 0.36 & 46.6 & 0.891 & 227.4 & 0.897 & 149.9 & 0.896 \\
\hline 0.43 & 39.7 & 0.894 & 116.6 & 0.901 & 89.9 & 0.901 \\
\hline 0.51 & 34.4 & 0.897 & 73.2 & 0.904 & 43.2 & 0.902 \\
\hline 0.61 & 29.4 & 0.900 & 41.4 & 0.906 & 26.4 & 0.905 \\
\hline 0.80 & 22.1 & 0.901 & 20.4 & 0.909 & 13.5 & 0.906 \\
\hline 1.00 & 17.7 & 0.916 & 10.9 & 0.916 & 8.3 & 0.916 \\
\hline
\end{tabular}

Table 3. Global enthalpy for D2EHPA- and Cyanex 272-amine mixtures at $25{ }^{\circ} \mathrm{C}$ (uncertainties on mole fraction $= \pm 0.1 \%$, enthalpies $= \pm 3 \%$ ).

\begin{tabular}{|c|c|c|c|c|c|c|c|c|c|}
\hline \multicolumn{6}{|c|}{ D2EHPA } & \multicolumn{4}{|c|}{ Cyanex 272} \\
\hline \multicolumn{2}{|c|}{ TEHA } & \multicolumn{2}{|c|}{ TIOA } & \multicolumn{2}{|c|}{ TOA } & \multicolumn{2}{|c|}{ TIOA } & \multicolumn{2}{|c|}{ TOA } \\
\hline$x$ (amine) & $\mathrm{H}\left(\mathrm{J} \cdot \mathrm{mol}^{-1}\right)$ & $x$ (amine) & $\mathrm{H}\left(\mathrm{J} \cdot \mathrm{mol}^{-1}\right)$ & $x$ (amine) & $\mathrm{H}\left(\mathrm{J} \cdot \mathrm{mol}^{-1}\right)$ & $x$ (amine) & $\mathrm{H}\left(\mathrm{J} \cdot \mathrm{mol}^{-1}\right)$ & $x$ (amine) & $\mathrm{H}\left(\mathrm{J} \cdot \mathrm{mol}^{-1}\right)$ \\
\hline 0.11 & -4331.0 & 0.20 & $-10,498.8$ & 0.10 & -6780.1 & 0.10 & -2794.0 & 0.10 & -2824.5 \\
\hline 0.23 & -7605.3 & 0.30 & $-12,514.6$ & 0.21 & $-13,137.3$ & 0.20 & -5611.7 & 0.20 & -6640.6 \\
\hline 0.41 & -6831.8 & 0.38 & $-14,455.3$ & 0.31 & $-17,921.9$ & 0.30 & -6640.2 & 0.30 & -7346.5 \\
\hline 0.50 & -6375.6 & 0.49 & $-14,446.2$ & 0.40 & $-17,900.4$ & 0.39 & -6342.3 & 0.38 & -7132.9 \\
\hline 0.56 & -5950.2 & 0.59 & $-13,809.4$ & 0.57 & $-14,032.3$ & 0.50 & -6006.0 & 0.50 & -5794.3 \\
\hline 0.66 & -4811.6 & 0.67 & $-12,617.9$ & 0.71 & $-10,513.4$ & 0.60 & -5513.4 & 0.59 & -4888.8 \\
\hline 0.75 & -3993.5 & 0.78 & -8095.2 & 0.90 & -3609.2 & 0.70 & -4110.0 & 0.69 & -3814.1 \\
\hline \multirow[t]{2}{*}{0.86} & -1828.6 & 0.89 & -4299.0 & & & 0.80 & -3027.1 & 0.82 & -2147.2 \\
\hline & & & & & & 0.90 & -1802.3 & 0.90 & -1349.5 \\
\hline
\end{tabular}

\section{Results and Discussion}

\subsection{Physicochemical Properties}

Figure 1 shows the variation of the dynamic viscosity of D2EHPA-amine and Cyanex 272-amine mixtures as a function of amine mole fraction at $25^{\circ} \mathrm{C}$ (values are reported in Tables 1 and 2). The dynamic viscosity increases until a threshold value $\left(x_{a m i n e, m a x}\right)$, and then decreases, when amine is added into Cyanex 272 or D2EHPA. This threshold value $x_{a m i n e, m a x}$ depends on the type of amine added into the organophosphorus compound and corresponds to the formation of an ionic liquid due to the reaction between the amine and the organophosphorus acid. It is interesting to point out that no maximum of viscosity for the Cyanex 272-TEHA mixture is not observed likely because the maximum of viscosity is located at very low mole fraction of amine. In the binary mixtures, the organophosphorus acid acts as a proton donor while a primary, secondary or tertiary amine has unshared electron pair on the nitrogen atom. Therefore, an amine has the tendency to react with an acidic extractant. In general, three kinds of interaction may occur between acid and amine extractants, i.e., (i) ion-pair $\left(\mathrm{R}_{3} \mathrm{NH}^{+}\right.$, $\mathrm{A}^{-}$), (ii) hydrogen bonding $\left(\mathrm{R}_{3} \mathrm{NH}-\mathrm{A}\right)$ and (3) binding which has an intermediate characteristic as represented by the location of the proton $\left(\mathrm{R}_{3} \mathrm{~N}-\mathrm{H}-\mathrm{A}\right)[17,18]$. The nature of the interactions in the mixture depends on the properties of the extractants involved as well as the concentration ratio of components. 
(a)

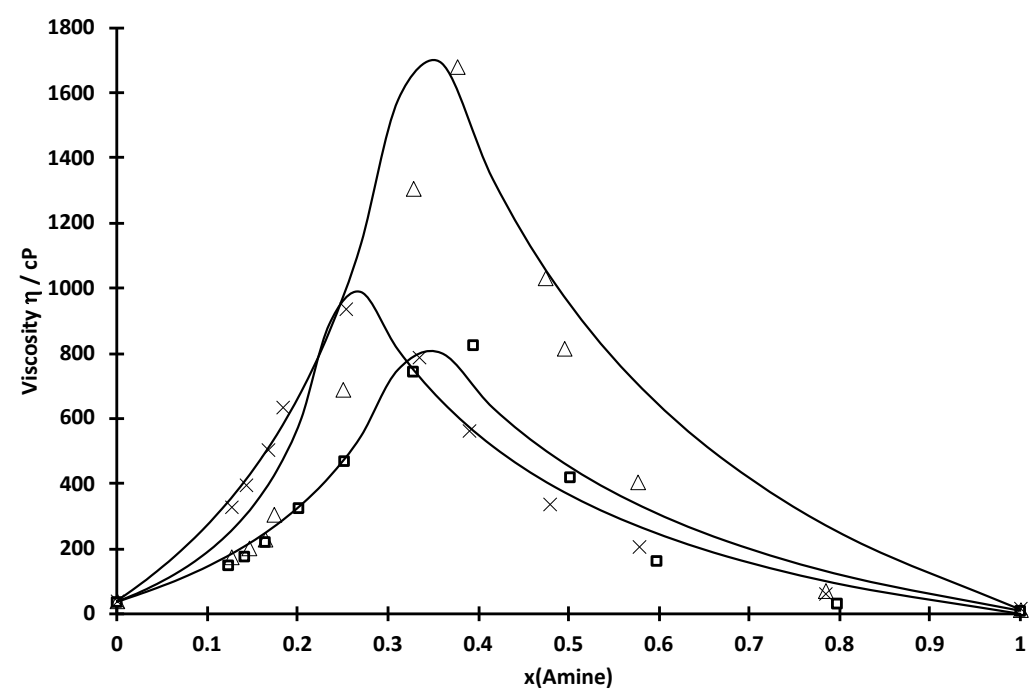

(b)

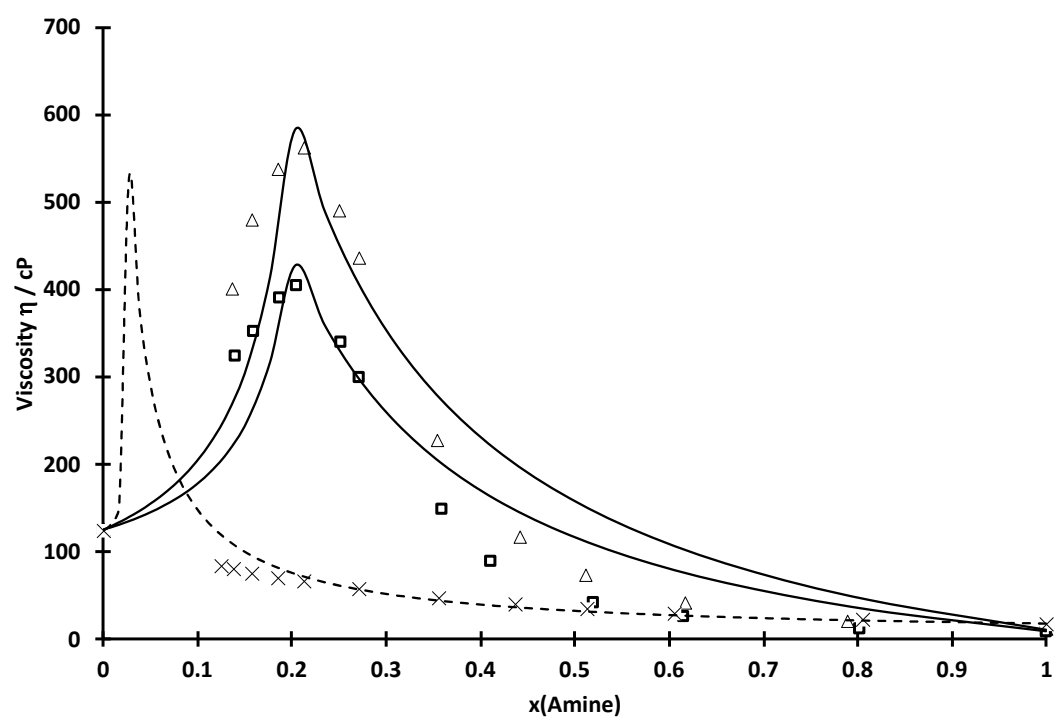

Figure 1. Viscosity of (a) D2EHPA-amine and (b) Cyanex 272-amine mixtures as a function of mole fraction of TOA (square), TIOA (triangle) and TEHA (cross) at $25^{\circ} \mathrm{C}$.

The increase in the dynamic viscosity may be explained by the reaction between the amine and D2EHPA or Cyanex 272, which may lead to the formation of solvated ion pairs by strong electrostatic interactions:

$$
\mathrm{R}_{3} \mathrm{~N}+\mathrm{aHL} \rightarrow\left\{\mathrm{R}_{3} \mathrm{NH}^{+}, \mathrm{L}^{-}\right\}(\mathrm{HL})_{\mathrm{a}-1}
$$

When $x_{a m i n e}<x_{a m i n e, m a x}, H L$ is in excess and the mixture contains $\mathrm{HL}$ and $\left\{\mathrm{R}_{3} \mathrm{NH}^{+}, \mathrm{L}^{-}\right\}(\mathrm{HL})_{\mathrm{a}-1}$. The $\eta$-values increase due to the increase in the concentration of the highly viscous species $\left\{\mathrm{R}_{3} \mathrm{NH}^{+}\right.$, $\left.\mathrm{L}^{-}\right\}(\mathrm{HL})_{\mathrm{a}-1}$. The maximum value of viscosity $\left(\eta_{\max }\right)$ is, thus, reached when only $\left\{\mathrm{R}_{3} \mathrm{NH}^{+}, \eta\right.$-values \}$(\mathrm{HL})_{\mathrm{a}-1}$ is present in the solution, i.e., when the mole fraction of the amine corresponds to the stoichiometric ratio between the amine and the HL.

In the rich-amine region, the $\left\{\mathrm{R}_{3} \mathrm{NH}^{+}, \mathrm{L}^{-}\right\}(\mathrm{HL})_{\mathrm{a}-1}$ species might react with the amine to form another highly viscous species, i.e., $\left\{\mathrm{R}_{3} \mathrm{NH}^{+}, \mathrm{L}^{-}\right\}$: 


$$
\left\{\mathrm{R}_{3} \mathrm{NH}^{+}, \mathrm{L}^{-}\right\}(\mathrm{HL})_{\mathrm{a}-1}+(\mathrm{a}-1) \mathrm{R}_{3} \mathrm{~N} \rightarrow \mathrm{a}\left\{\mathrm{R}_{3} \mathrm{NH}^{+}, \mathrm{L}^{-}\right\}
$$

However, the decrease in dynamic viscosity when the amine is added in excess into the organophosphorus acid cannot be explained by the formation of $\left\{\mathrm{R}_{3} \mathrm{NH}^{+}, \mathrm{L}^{-}\right\}$as the viscosity of this species is likely more or less the same as $\left\{\mathrm{R}_{3} \mathrm{NH}^{+}, \mathrm{L}^{-}\right\}(\mathrm{HL})_{\mathrm{a}-1}$. Therefore, the decrease in the dynamic viscosity for $x_{\text {amine }}>x_{a m i n e, m a x}$ (amine in excess to organophosphorus acid) is likely due to the dilution of the amine-organophosphorus species (it is not possible to give the exact nature of this species as it can be an ion pair formed between the amine and the organophosphorus acid or the other species above-mentioned, i.e., $\mathrm{R}_{3} \mathrm{NH}-\mathrm{A}$ (hydrogen bonding) or $\left(\mathrm{R}_{3} \mathrm{~N}-\mathrm{H}-\mathrm{A}\right)$, which is an intermediate species with proton delocalized between the amine and the conjugated base of the acidic extractant).

Examination of the dynamic viscosity values as a function of the type of the amine in the mixtures shows that the dynamic viscosity is dependent on the chemical structure of the amine and varies as follows: TIOA >> TEHA > TOA. Branches in alkyl chains of the amines seem to hinder the flow transport the flow transport. Furthermore, the D2EHPA-amine mixtures exhibit higher viscosity values than the Cyanex 272-amine mixtures. This is in accordance with the previous studies $[10,19]$ and with the fact that interactions between an amine and an acid extractant are proportional to the acidity of the acididic extractants (acidity of D2EHPA is greater than that of Cyanex 272 in view of $\mathrm{pK}_{\mathrm{a}}$ values [20]). Liu et al. [10] estimated that the strength of the interactions between D2EHPA and Alamine 336 (mainly composed of tri-n-octylamine) is about three times as strong as Cyanex 272 and Alamine 336 by calculating excess values of dielectric constants.

Molar volumes at $25{ }^{\circ} \mathrm{C}$ of the D2EHPA-amine and Cyanex 272-amine mixtures have been calculated from density values reported in Tables 1 and 2 . The difference of molar volume at $25^{\circ} \mathrm{C}$ $\left(V_{m}{ }^{\neq}\right)$was calculated by using the following equation:

$$
V_{m}^{\neq}=\frac{\left(x_{1} M_{1}+x_{2} M_{2}\right)}{\rho}-\left(\frac{x_{1} M_{1}}{\rho_{1}}+\frac{x_{2} M_{2}}{\rho_{2}}\right)
$$

where $\rho$ is the density of the solution, $\rho_{1}$ and $\rho_{2}$ are the densities of an amine (TOA, TIOA, TEHA) and an organophosphorus acid (D2EHPA or Cyanex 272), respectively. $M_{1}$ and $M_{2}$ are molecular weights of an amine and an organophosphorus acid, respectively. It is interesting to notice that excess volume molar cannot be defined in this case because of the reaction between amine and organophosphorus extractants (excess molar functions can be defined only providing that there is no chemical reaction during mixing).

The variations of $V_{m}{ }^{\neq}$as a function of the mole fraction of an amine in the D2EHPA-amine and Cyanex 272-amine mixtures were fitted by using the following Redlich-Kister equation (Figure 2) [21]:

$$
V_{m}^{\neq}=x_{1}\left(1-x_{1}\right) \sum_{i=0}^{n} A_{i}\left(2 x_{1}-1\right)^{i}
$$

where $x_{1}$ represents the mole fraction of an amine in the D2EHPA and Cyanex 272-amine mixtures. The values of the adjustable parameters $A_{i}$ in Equation (8) are gathered in Table 3.

$V_{m}{ }^{\neq}$gives information on ion pair formation [Equations (5) and (6)] and interaction changes when an amine is added into Cyanex 272 or D2EHPA. In the D2EHPA-amine mixtures, there is no real influence of the chemical structure of the amine on the strength of the electrostatic interactions (and therefore the stability of the ion-pairs formed between D2EHPA and an amine) since $V_{m}{ }^{\neq}$values are quite similar for the D2EHPA-TOA, D2EHPA-TIOA and D2EHPA-THEA mixtures.

More important differences in $V_{m}{ }^{\neq}$values are observed for the Cyanex 272-amine mixtures as $V_{m} \neq$ values in the presence of TEHA mixtures are lower than those obtained for Cyanex 272-TIOA and Cyanex 272-TOA mixtures. Branching of amine seems to destabilize Cyanex 272-amine ion pairs. 
Furthermore, it is interesting to highlight that the minimum of $V_{m} \neq$ is located at the same mole fraction as the maximum of viscosity for all investigated systems. This is not really surprising as a minimum of $V_{m} \neq$ denotes the presence of strong interactions in the solution such as electrostatic interactions arising from ion-pairs formation of $\left\{\mathrm{R}_{3} \mathrm{NH}^{+}, \mathrm{L}^{-}\right\}(\mathrm{HL})_{\mathrm{a}-1}$.

(a)

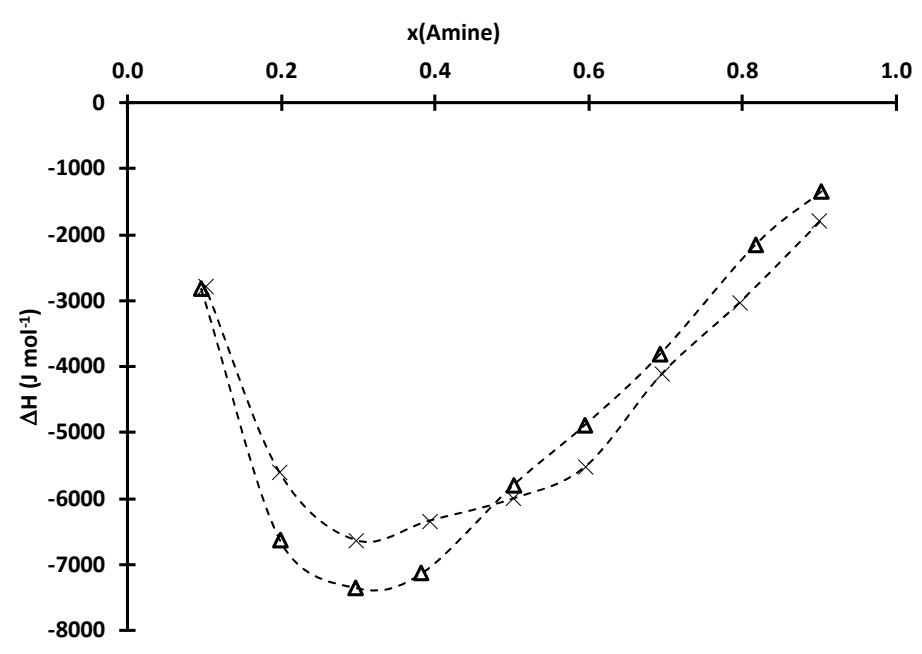

(b)

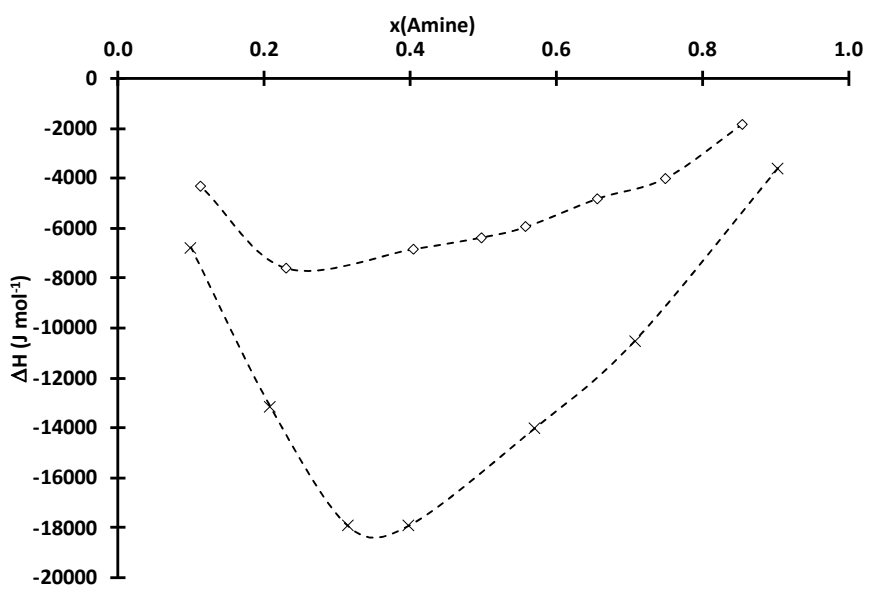

Figure 2. Global enthalpy during mixing of (a) Cyanex 272 and (b) D2EHPA with TIOA (cross), TOA and TEHA (diamond) as a function of mole fraction of the amine at $25^{\circ} \mathrm{C}$.

Calorimetric measurements reported in Figure 3 were performed to study the influence of mole fraction of an amine on the global enthalpy expressed as:

$$
H=H^{m i x}+\Delta_{r} H
$$

where $H^{m i x}$ and $\Delta_{r} H$ denote the enthalpy of mixture and the enthalpy of the reaction reported in Equation (5), respectively, when an amine is added into D2EHPA or Cyanex 272.

It is not possible to discriminate $H^{\text {mix }}$ and $\Delta_{r} H$. However, $H^{\text {mix }}$ is likely negative since strong attractive forces between the mixed molecules usually result in a release of heat. Likewise, acid-base reactions usually exhibit negative values. As a consequence, the global enthalpy of a mixture is 
negative. The minima of the global enthalpies are located at the same mole fractions of amine as those observed for $\eta$ and $V_{m}{ }^{\neq}$(Figures 1 and 2).

There is no significant difference in global enthalpies for Cyanex 272-TIOA and Cyanex 272-TOA likely because there is no significant difference in enthalpy of the reaction between these systems, and because the electrostatic interactions are of the same order of magnitude as it was confirmed by comparing $V_{m}{ }^{\ddagger}$ values (see above). Conversely, the global enthalpies obtained for the D2EHPA-TIOA mixtures are drastically greater than those obtained for the D2EHPA-TEHA mixtures. This difference can be explained by the existence of a very exothermic reaction between D2EHPA and TEHA since the analysis of $V_{m}{ }^{*}$ in Figure 3 showed the magnitude of the electrostatic interactions between D2EHPA and TIOA or TEHA are similar.

(a)

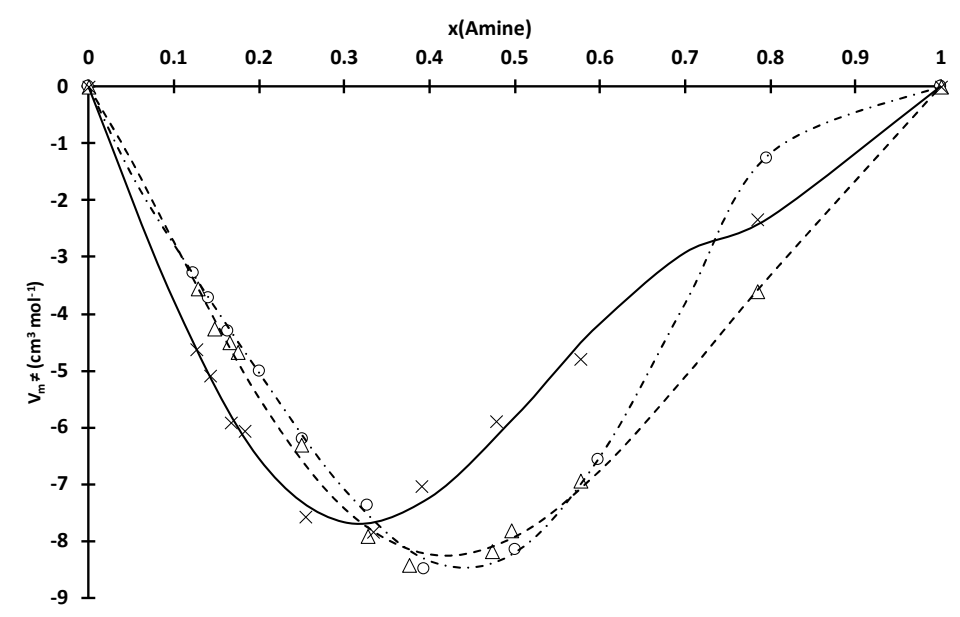

(b)

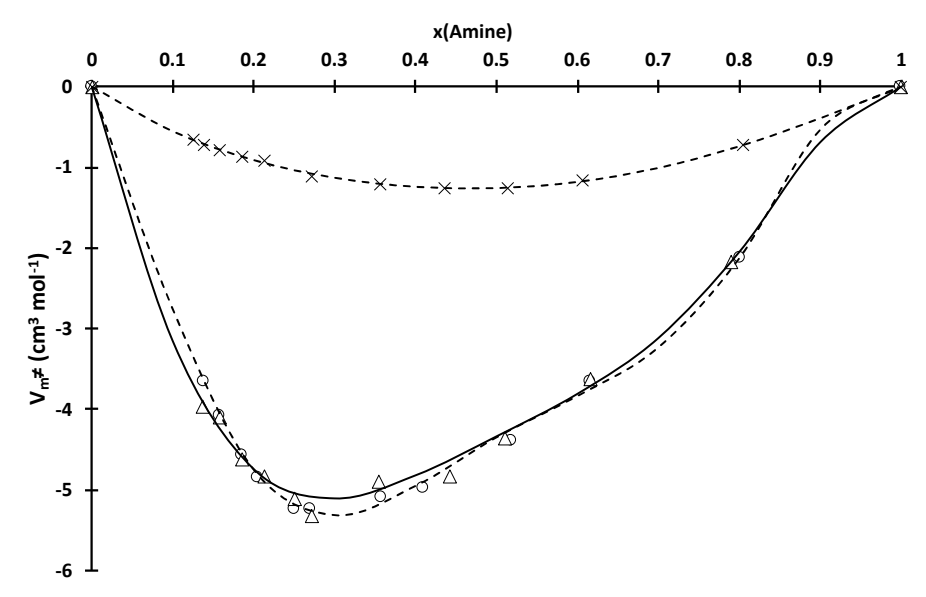

Figure 3. Difference in molar volume $\left(V_{m}{ }^{\neq}\right.$, see Equation 7$)$ at $25^{\circ} \mathrm{C}$ as a function of mole fraction of the amine for mixtures of (a) D2EHPA or (b) Cyanex 272 and TOA (circle), TIOA (triangle) and TEHA (cross). Experimental points were fitted with Redlich-Kister equation (see Equation (8) and Table 4).

The variation of the viscosity $(\eta)$ in the D2EHPA-amine or Cyanex 272-amine mixtures as a function of mole fraction of amine $\left(\mathrm{x}_{1}\right)$ can be expressed by using the following equation:

$$
\eta=x_{1} \eta_{1}+\left(1-x_{1}\right) \eta_{2}+x_{I P} \eta_{I P}+\eta^{E X}
$$


where $\eta_{1}, \eta_{2}, \eta_{I P}$ and $\eta^{E X}$ denote the viscosity of the pure amine, the pure organophosphorus acid (D2EHPA or Cyanex 272), the ion pair $\left\{\mathrm{R}_{3} \mathrm{NH}^{+}, \mathrm{L}^{-}\right\}(\mathrm{HL})_{\mathrm{a}-1}$ as well as the excess of viscosity due to interaction in the solution (non-ideality).

It is therefore possible to calculate the variation of the viscosity as a function of the mole fraction of amine by considering, in a first approximation, that the system is ideal (Equation (10) with $\eta^{\mathrm{EX}}=0$ ). The straight lines in Figure 1 represent the results of the calculations with the most appropriate values of $\eta_{I P}$ (estimated value of the dynamic viscosity of $\left\{\mathrm{R}_{3} \mathrm{NH}^{+}, \mathrm{L}^{-}\right\}(\mathrm{HL})_{\mathrm{a}-1}$ ) and the most appropriate values of the stoichiometric ratio (a) (see Table 5). The corresponding chemical formulae of each ion-pairs expected to be formed in the Cyanex 272- and D2EHPA-amine mixtures are reported in Table 5. From these results, it was also possible to deduce the speciation in these mixtures as a function of the mole fraction of the amine (Figure 4).

Table 4. Redlich-Kister parameters of $V_{m} \neq$ at $25{ }^{\circ} \mathrm{C}$ for the D2EHPA-amine and Cyanex 272-amine mixtures.

\begin{tabular}{ccccccc}
\hline & \multicolumn{3}{c}{ D2EHPA } & \multicolumn{3}{c}{ Cyanex 272 } \\
\hline & TOA & TIOA & TEHA & TOA & TIOA & TEHA \\
\hline A & -28.164 & 0 & 0 & 31.791 & 7.294 & 0 \\
B & 3.242 & -12.909 & -30.578 & 3.910 & 4.519 & 0.832 \\
C & 47.528 & 11.669 & -12.034 & -22.358 & -12.723 & -0.362 \\
D & 18.944 & 15.831 & 33.124 & 12.240 & 12.272 & 9.594 \\
E & -32.904 & -31.707 & -23.300 & -17.542 & -17.657 & -5.050 \\
\hline
\end{tabular}

Table 5. Stoichiometry of the amine-organophosphorus species in ionic liquids.

\begin{tabular}{ccc}
\hline & D2EHPA & Cyanex 272 \\
\hline \multirow{3}{*}{ TOA } & $\mathrm{a}=2$ & $\mathrm{a}=4$ \\
& $\mathrm{R}_{3} \mathrm{NHL}(\mathrm{HL})$ & $\mathrm{R}_{3} \mathrm{NHL}(\mathrm{HL})_{3}$ \\
& $\eta_{\mathrm{IP}}=900 \mathrm{cP}$ & $\eta_{\mathrm{IP}}=440 \mathrm{cP}$ \\
TIOA & $\mathrm{a}=2$ & $\mathrm{a}=4$ \\
& $\mathrm{R}_{3} \mathrm{NHL}(\mathrm{HL})$ & $\mathrm{R}_{3} \mathrm{NHL}(\mathrm{HL})_{3}$ \\
& $\eta_{\mathrm{IP}}=1900 \mathrm{cP}$ & $\eta_{\mathrm{IP}}=600 \mathrm{cP}$ \\
& $\mathrm{a}=3$ & \\
TEHA & $\mathrm{R}_{3} \mathrm{NHL}(\mathrm{HL})_{2}$ & - \\
& $\eta_{\mathrm{IP}}=1100 \mathrm{cP}$ & \\
\hline
\end{tabular}

The maximum values of viscosity calculated by this simple model are in a good agreement with the experimental data. Obviously, there are discrepancies between the calculated and the experimental values of $\eta$ for rich and poor-amine mixtures as the model considers an ideal mixture. Values of $\eta_{I P}$ reported in Table 5 show that the electrostatic interactions between D2EHPA and an amine are stronger than those between Cyanex 272 and an amine in accordance with the study of molar volumes (see above).

\subsection{Effect of Amine Molar Fraction on the Liquid-Liquid Extraction Properties of the Ionic Liquids}

Performances in liquid-liquid extraction depend mainly on extractant-extractant and metal-extractant interactions in the absence of diluent like in the present case. The preceding results mentioned above have shown that the strength of the interactions between D2EHPA and an amine are stronger than between Cyanex 272 and an amine. In this part, the influence of an amine in the D2EHPA-amine mixtures on cobalt(II) extraction from acidic chloride media has been investigated because it is expected that the strong interactions between D2EHPA and an amine will favor the formation of $\left\{\mathrm{R}_{3} \mathrm{NH}^{+}, \mathrm{L}^{-}\right\}(\mathrm{HL})_{\mathrm{a}-1}$. In particular, the influence of chloride concentration and the nature of an amine on cobalt(II) extraction and cobalt(II)-nickel(II) separation have been investigated. 
Figure 5 shows extraction efficiencies of cobalt(II) from acidic chloride solutions (chloride concentrations ranging from 0.1 to $5 \mathrm{~mol} \cdot \mathrm{L}^{-1}$ ) by D2EHPA mixed with TOA, TIOA or TEHA) at different mole fractions of the amine. Mole fractions of the amine have been chosen in order to evaluate the influence of the speciation in the organic phase on cobalt(II) extraction. In particular, three regions have been studied: (i) mole fraction of the amine lower than the mole fraction corresponding to the maximum of viscosity as free D2EHPA is predominant, (ii) mole fraction of the amine equal to the maximum of viscosity as $\left\{\mathrm{R}_{3} \mathrm{NH}^{+}, \mathrm{L}^{-}\right\}(\mathrm{HL})_{\mathrm{a}-1}$ is the main species, and (iii) mole fraction of the amine greater than the mole fraction corresponding to the maximum of viscosity as the free amine is the predominant species in this region (see Figures 1 and 4).

(a)

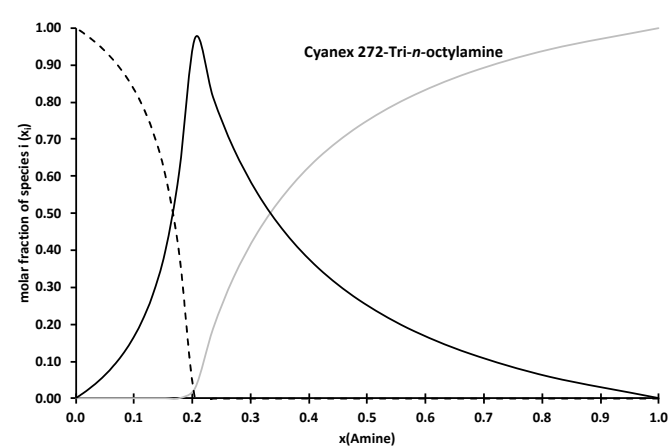

(b)

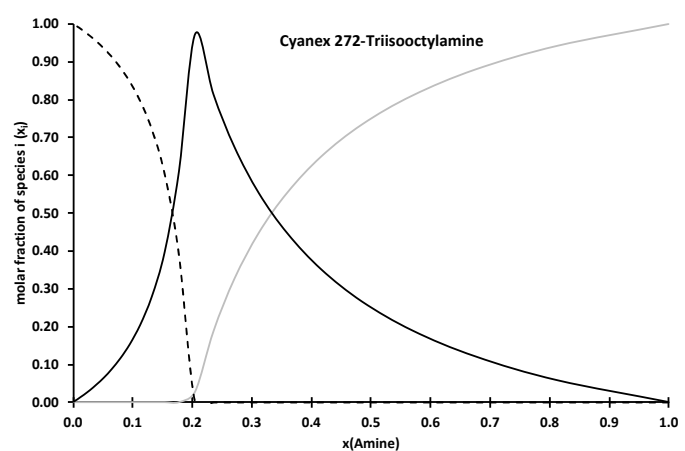

(c)

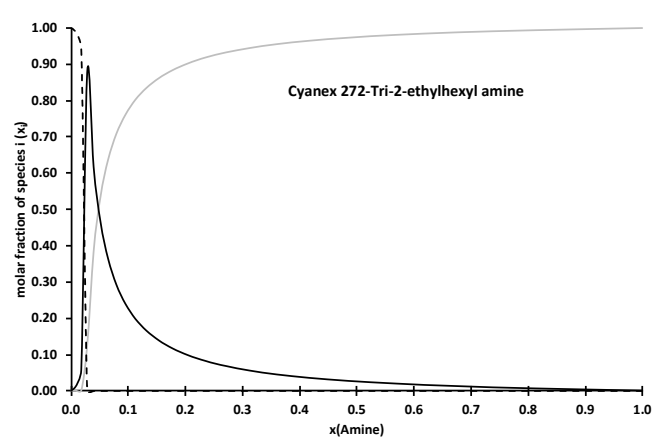

(d)

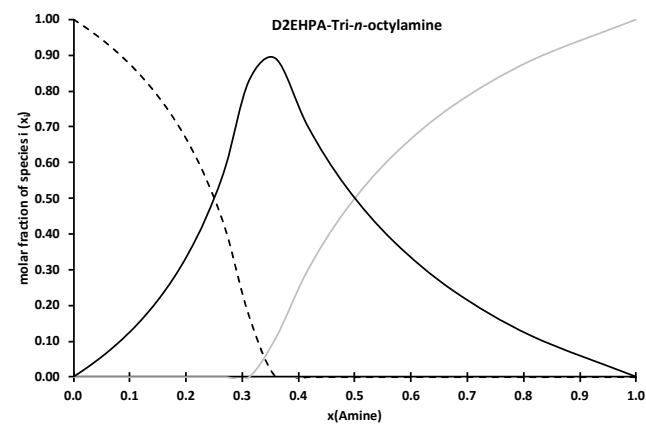

(e)

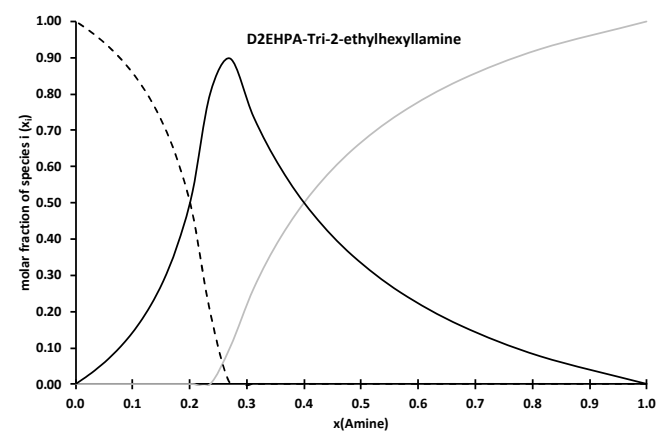

(f)

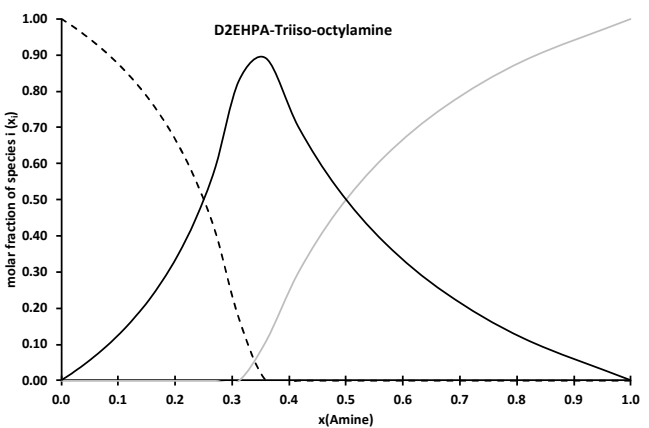

Figure 4. Speciation diagrams at $25^{\circ} \mathrm{C}$ in mixtures of Cyanex $272(\mathbf{a}-\mathbf{c})$ or D2EHPA $(\mathbf{d}-\mathbf{f})$ and TOA, TIOA and TEHA as a function of mole fraction of the amine (gray curve $=$ free amine, dotted line $=$ free organophosphorus acid, black line $=\mathrm{R}_{3} \mathrm{NHL}(\mathrm{HL})_{\mathrm{a}-1}$ species). 
At a mole fraction of the amine lower than the maximum of viscosity, no cobalt(II) extraction occurs for chloride concentration lower than $5 \mathrm{~mol} \cdot \mathrm{L}^{-1}$ whatever the nature of the amine mixed with D2EHPA. At $5 \mathrm{~mol} \cdot \mathrm{L}^{-1}$ of chloride, only the mixtures containing TOA and TEHA extract cobalt(II) but the extraction efficiency remains very low. Cobalt(II) is likely not extracted by TOA or TEHA)-D2EHPA mixtures at $x$ (amine) $=0.2$ because there is no free amine (Figure $3 \mathrm{~d}, \mathrm{e})$. Conversely, cobalt(II) may be partially extracted by $\left\{\mathrm{R}_{3} \mathrm{NH}^{+}, \mathrm{L}^{-}\right\}(\mathrm{HL})_{\mathrm{a}-1}$ via an anion extraction equilibria $(\mathrm{a}=2$ for TOA and $\mathrm{a}=3$ for TEHA).

At mole fraction of the amine corresponding to the maximum of viscosity in Figure 1 , only $\left\{\mathrm{R}_{3} \mathrm{NH}^{+}\right.$, $\left.\mathrm{L}^{-}\right\}(\mathrm{HL})_{\mathrm{a}-1}$ species are present in solution. Figure $5 \mathrm{c}$ shows that cobalt(II) extraction is greatly increased. It confirms that $\left\{\mathrm{R}_{3} \mathrm{NH}^{+}, \mathrm{L}^{-}\right\}(\mathrm{HL})_{\mathrm{a}-1}$ can efficiently extract cobalt(II). However, extraction efficiency depends on both chloride concentration and the nature of the amine. The higher the chloride concentration, the higher the cobalt extraction. This is not surprising since the extraction involves an anion exchange equilibria and cobalt mainly exists as anions at high chloride concentration $\left(\mathrm{CoCl}_{3}{ }^{-}\right.$ and $\mathrm{CoCl}_{4}{ }^{2-}$ ) [22,23]. Figure 5c shows that extraction performance increases in the following order: TEHA $<$ TIOA $<$ TOA. However, it is interesting to point out that cobalt(II) extraction by TIOA and TOA tends to be similar at chloride concentration greater than $3 \mathrm{~mol} \cdot \mathrm{L}^{-1}$. This is in accordance with the physicochemical part of this paper, which showed that branching of an amine seems to destabilize electrostatic interactions in solution. Therefore, the low extraction efficiency in D2EHPA-amine mixtures containing branched amine might result from low stability of $\left\{\mathrm{R}_{3} \mathrm{NH}^{+}, \mathrm{L}^{-}\right\}(\mathrm{HL})_{\mathrm{a}-1}$ species.

(a)

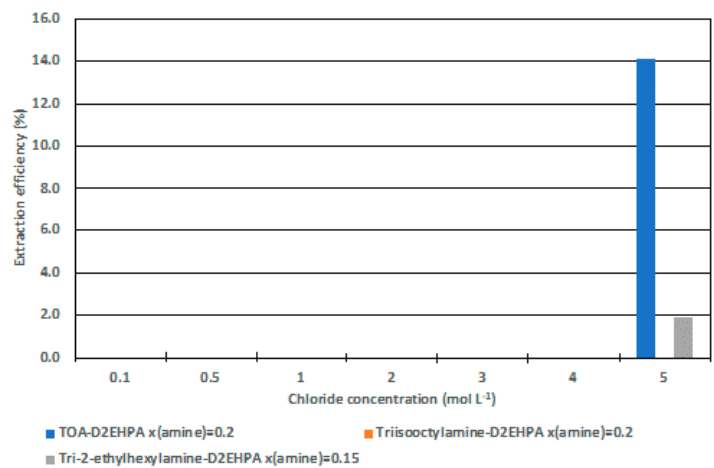

(b)

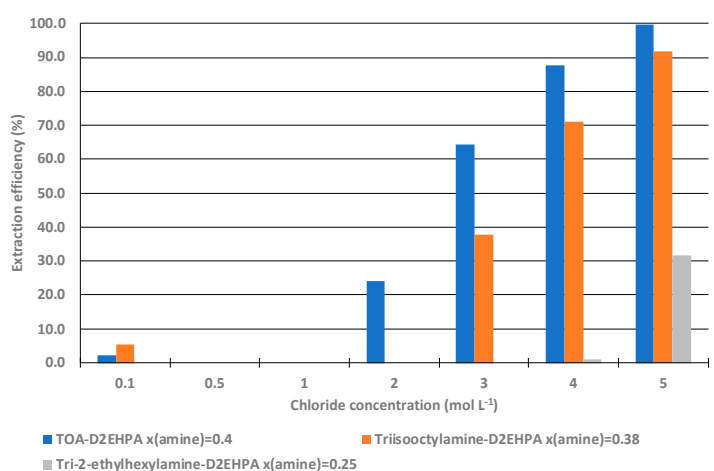

(c)

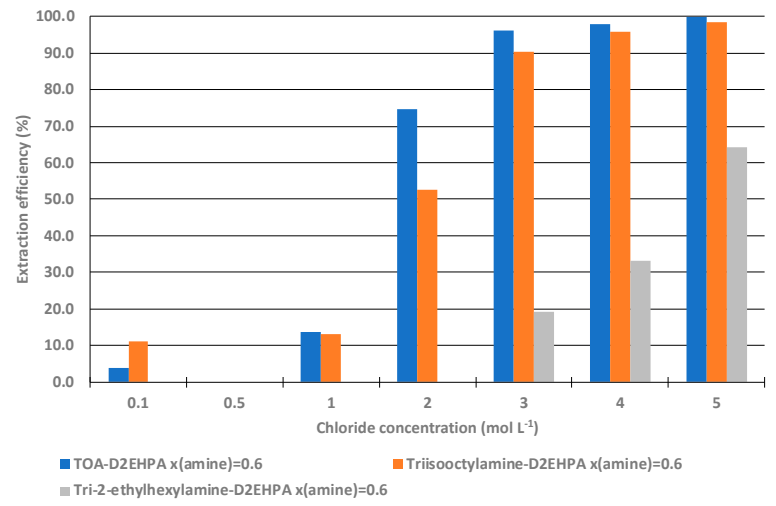

Figure 5. Extraction efficiency of cobalt vs. initial chloride concentration by the D2EHPA-amine mixtures at different mole fractions of the amine in (a), (b) and (c), i.e., before, after and at the maximum of viscosity observed reported in Figure 1. Organic to aqueous phase volume ratio $\mathrm{O} / \mathrm{A}=1$; initial concentration of cobalt $=0.008 \mathrm{~mol} \cdot \mathrm{L}^{-1}$.

Figure $5 c$ confirms that an increase in mole fraction of the amine is responsible for an increase in cobalt(II) extraction efficiency. Figure $4 d-f$ shows $\left\{\mathrm{R}_{3} \mathrm{NH}^{+}, \mathrm{L}^{-}\right\}(\mathrm{HL})_{\mathrm{a}-1}$ concentration decreases at the 
extent of an increase in the free amine concentration. Therefore, cobalt(II) extraction may involve two simultaneous extraction equilibria involving $\left\{\mathrm{R}_{3} \mathrm{NH}^{+}, \mathrm{L}^{-}\right\}(\mathrm{HL})_{\mathrm{a}-1}$ and the free amine when amine mole fraction is greater than the mole fraction corresponding to the maximum of viscosity. The presence of two species exhibiting extractive properties towards cobalt(II) is responsible for better cobalt(II) extraction efficiency.

The cobalt(II)-nickel(II) selectivity has been also investigated with D2EHPA-amine mixtures at $x($ amine $)=0.6$ as a function of chloride concentration (Figure 6). For all mixtures, the selectivity decreases when chloride concentration increases. Similar extraction behaviour is observed between the D2EHPA-TOA and D2EHPA-TIOA mixtures and these systems exhibit low selectivity. The highest selectivity is obtained for D2EHPA-TEHA mixture as cobalt(II) extraction efficiency is equal to $77 \%$ at a chloride concentration of $3 \mathrm{~mol} \cdot \mathrm{L}^{-1}$ while there is no significant nickel(II) extraction.

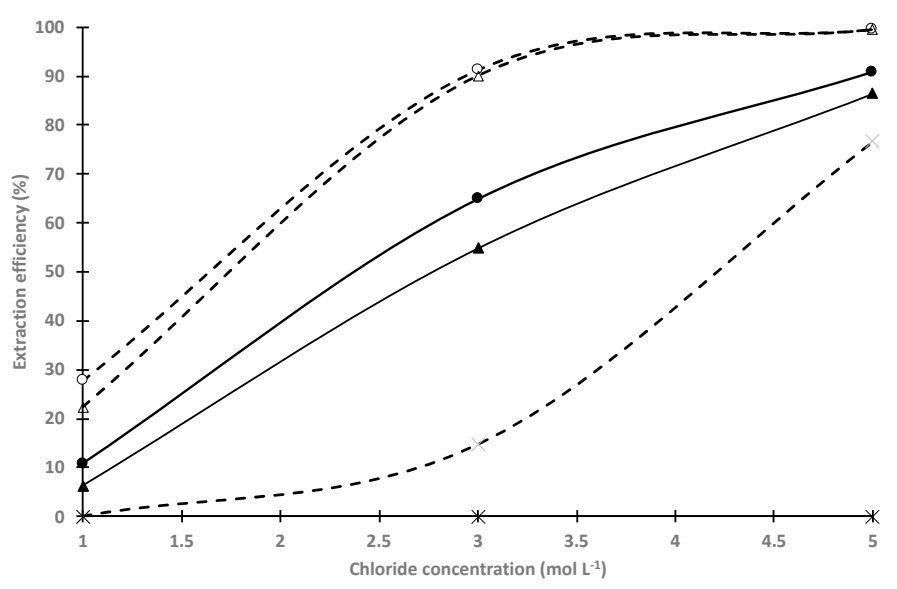

Figure 6. Comparison of cobalt extraction and nickel extraction efficiencies vs. initial chloride concentration by the D2EHPA-amine mixtures at different mole fractions of the amine (before, after and at the maximum of viscosity observed in Figure 1). White/doted-line: cobalt extraction; black/straight line: nickel extraction; circle: TOA-D2EHPA; triangle: TIOA-D2EHPA; cross: TEHA-D2EHPA. O/A = 1; initial concentration of cobalt and nickel $=0.008 \mathrm{~mol} \cdot \mathrm{L}^{-1}$.

\section{Conclusions}

Viscosity, density and enthalpy have been determined at $25^{\circ} \mathrm{C}$ in order to bring information about interactions and speciation in mixtures of organophosphorus acid (D2EHPA and Cyanex 272) and amine (TEHA, TIOA, TOA) as well as the effect of amine on the structuration/destructuration of the ionic liquids. As expected, this study shows interactions between D2EHPA and the amine are greater than between Cyanex 272 and the amine in accordance with the highest acidity of D2EHPA. This results likely in higher stability of D2EHPA-amine ionic liquids than Cyanex 272-amine ionic liquids. This results in higher viscosity of the D2EHPA-amine mixtures than the Cyanex 272 systems. However, the magnitude of the difference between the experimental molar volume and the ideal molar volume in absence of interaction and reaction is almost the same whatever the nature of organophosphorus acid or amine. This means that the addition of the amine in the organophosphorus acid does not significantly organize the solution in spite of the formation of the strong interactions. Conversely, it appears that branching of the amine destabilizes electrostatic interactions in solution. A simple model describing the variation of the viscosity as a function of amine mole fraction shows the presence of free amine, free D2EHPA or free Cyanex 272 and $\left\{\mathrm{R}_{3} \mathrm{NH}^{+}, \mathrm{L}^{-}\right\}(\mathrm{HL})_{\mathrm{a}-1}$ in organophosphorus compound-amine mixtures at various concentration depending on the mole fraction of the amine.

Extraction tests of D2EHPA-amine mixtures at various mole fraction of the amine show that $\left\{\mathrm{R}_{3} \mathrm{NH}^{+}, \mathrm{L}^{-}\right\}(\mathrm{HL})_{\mathrm{a}-1}$ can extract cobalt(II). The extraction efficiency depends on the percentage of the free amine and $\left\{\mathrm{R}_{3} \mathrm{NH}^{+}, \mathrm{L}^{-}\right\}(\mathrm{HL})_{\mathrm{a}-1}$ present in solution. The highest selectivity is obtained with 
D2EHPA-TEHA mixture ( $x$ (amine) $=0.6$ ) as cobalt(II) extraction efficiency is equal to $77 \%$ at a chloride concentration of $3 \mathrm{~mol} \cdot \mathrm{L}^{-1}$ while there is no significant nickel(II) extraction.

Author Contributions: Conceptualization, supervision, funding acquisition, writing -review and editing: A.C.; Viscosity and density measurements: S.G.; Calorimetric measurements: F.M. All authors have read and agreed to the published version of the manuscript.

Funding: This work was supported by the French National Research Agency through the national program "Investissements d'avenir" with the reference ANR-10-LABX-21-RESSOURCES21 and the French National Research Agency through the national program 'Appel à Projet Générique 2018' (ANR-18-CE08-0005-03).

Conflicts of Interest: The authors declare no conflict of interest.

\section{References}

1. Chagnes, A. Fundamentals in Electrochemistry and Hydrometallurgy. In Lithium Process Chemistry: Resources, Extractions, Batteries and Recycling, 1st ed.; Chagnes, A., Swiatowska, J., Eds.; Elsevier: Amsterdam, The Netherlands, 2015; pp. 41-80.

2. Prestianni, A.; Joubert, L.; Chagnes, A.; Cote, G.; Adamo, C. A Density Functional Theory Study of Uranium (VI) Nitrate Monoamides Complexes. Phys. Chem. Chem. Phys. 2011, 13, 19371-19377. [CrossRef]

3. Love, J.; Miguirditchian, M.; Chagnes, A. New Insights into the Recovery of Strategic and Critical Metals by Solvent Extraction. In Ion Exchange and Solvent Extraction, 1st ed.; Moyer, B.A., Ed.; CRC Press: Boca Raton, FL, USA, 2019; pp. 1-44.

4. Artese, A.; Dourdain, S.; Arrachart, G.; Pellet-Rostaing, S.; Boubals, N. Use of Bifunctional Compounds N, P for Extracting Uranium from Aqueous Solutions of Nitric Acid. In Proceedings of the JNRC-RANC, Budapest, Hungary, 5-10 May 2019.

5. Nash, K.L.; Choppin, G.R. Separations Chemistry for Actinide Elements: Recent Developments and Historical Perspective. Sep. Sci. Technol. 1997, 32, 255-274. [CrossRef]

6. Wilson, A.; Bailey, P.; Tasker, P.; Turkington, J.; Grant, R.; Love, J. Solvent Extraction: The Coordination Chemistry Behind Extractive Metallurgy. Chem. Soc. Rev. 2014, 43, 123-134. [CrossRef] [PubMed]

7. Kumar, B.N.; Reddy, B.R.; Kantam, M.L.; Kumar, J.R.; Lee, J.Y. Synergistic Solvent Extraction of Neodymium(III) from Chloride Solutions Using a Mixture of Triisooctylamine and Bis(2,4,4-Trimethylpentyl) Monothiophosphinic Acid. Sep. Sci. Technol. 2014, 49, 130-136. [CrossRef]

8. Liu, Y.; Jeon, H.S.; Lee, M.S. Solvent Extraction of Pr and Nd from Chloride Solution by The Mixtures of Cyanex 272 and Amine Extractants. Hydrometallurgy 2014, 150, 61-67. [CrossRef]

9. Banda, R.; Jeon, H.S.; Lee, M.S. Separation of Ce and La from Synthetic Chloride Leach Solution of Monazite Sand by Precipitation and Solvent Extraction. Metall. Mater. Trans. B 2014, 45, 2009-2017. [CrossRef]

10. Liu, Y.; Jeon, H.S.; Lee, M.S. Extraction of Hydrochloric Acid with Binary Mixtures of Tertiary Amine and Organophosphorus Acid and Analysis of the Interaction between the Constituents of these Mixtures. Hydrometallurgy 2015, 155, 44-50. [CrossRef]

11. Jiang, D.; Song, N.; Liao, S.; Lian, Y.; Ma, J.; Jia, Q. Study on the Synergistic Extraction of Vanadium by Mixtures of Acidic Organophosphorus Extractants and Primary Amine N1923. Sep. Purif. Technol. 2015, 156, 835-840. [CrossRef]

12. Jia, Q.; Zhan, C.; Li, D.; Niu, C. Extraction of Zinc(II) and Cadmium(II) by Using Mixtures of Primary Amine N1923 and Organophosphorus Acids. Sep. Sci. Technol. 2005, 39, 1111-1123. [CrossRef]

13. Kim, C.J.; Rajesh Kumar, J.; Kim, J.-S.; Lee, J.Y.; Yoon, H.-S. Solvent Extraction Studies on Uranium using Amine Based Extractants and Recovery from Low Grade Ore Leach Liquors. J. Braz. Chem. Soc. 2012, 23, 1254-1264. [CrossRef]

14. Grigorieva, N.A.; Pavlenko, N.I.; Pashkov, G.L.; Fleitlikh, I.Yu.; Nikiforova, L.K. Investigation of the State of Bis(2,4,4-Trimethylpentyl)Dithiophosphinic Acid in Nonane in the Presence of Electron Donor Additives. Solvent Extr. Ion Exch. 2010, 28, 510-525. [CrossRef]

15. Liu, Y.; Lee, M.S. Effect of the Diluents on the Interaction between Components in the Binary Mixtures of Organophosphorus Acid and Tertiary Amine. J. Mol. Liq. 2016, 220, 41-48. [CrossRef]

16. Abumandour, E.-S.; Mutelet, F.; Alonso, S. Performance of an Absorption Heat Transformer Using New Working Binary Systems Composed of ionic liquid and water. Appl. Therm. Eng. 2016, 94, 579-589. [CrossRef] 
17. Syzova, N.; Eyal, A.M.; Vitner, A.; Hazan, B. Interactions between the Components of ABC Extractants and Extraction of Monocarboxylic Acids by these Extractants. Solvent Extr. Ion Exch. 2004, 22, 31-49. [CrossRef]

18. Cholico Gonzalez, D.; Avila-Rodriguez, M.; Antonio Reyes-Aguilerad, J.; Cote, G.; Chagnes, A. Rheological behaviour of Cyphos IL101-Cyanex 272 Binary Mixtures between 288.15K and 343.15K. J. Mol. Liq. 2012, 169, $27-32$.

19. Liu, Y.; Lee, M.S. Determination of Viscosity and Dielectric Constant for Studying the Interactions in Binary Mixtures of Organophosphorus Acid and Tertiary Amine. J. Mol. Liq. 2016, 222, 233-238. [CrossRef]

20. Omelchuk, K.; Szczepański, P.; Shrotre, A.; Haddad, M.; Chagnes, A. Effects of Structural Changes of New Organophosphorus Cationic Exchangers on Solvent Extraction of Cobalt, Nickel and Manganese from Acidic Chloride Media. RSC Adv. 2017, 7, 5660-5668. [CrossRef]

21. Mialkowski, C.; Chagnes, A.; Carré, B.; Willmann, P.; Lemordant, D. Thermodynamic Properties of Binary Liquid Mixtures Containing Dimethyl Carbonate and $\gamma$-butyrolactone. J. Chem. Thermodyn. 2002, 34, 1845-1854. [CrossRef]

22. Liu, Y.; Seung Lee, M. Separation of Cobalt and Nickel from Chloride Leach Solution of Nickel Laterite Ore by Solvent Extraction. Geosystem Eng. 2016, 19, 214-221. [CrossRef]

23. Marcus, Y.Z.; Sengupta, A.K. Ion Exchange and Solvent Extraction; Marcel Dekker Inc.: New York, NY, USA, 2020.

Sample Availability: Samples of the compounds are not available from the authors. 